\title{
Cinémas
}

Revue d'études cinématographiques

Journal of Film Studies

\section{Clerc, Jeanne-Marie. Assia Djebar. Écrire, transgresser, résister. Paris : L'Harmattan, 1997, 173 p.}

\section{Jacqueline Viswanathan}

Volume 10, numéro 2-3, printemps 2000

Cinéma et intermédialité

URI : https://id.erudit.org/iderudit/024826ar

DOI : https://doi.org/10.7202/024826ar

Aller au sommaire du numéro

Éditeur(s)

Cinémas

ISSN

1181-6945 (imprimé)

1705-6500 (numérique)

Découvrir la revue

Citer ce compte rendu

Viswanathan, J. (2000). Compte rendu de [Clerc, Jeanne-Marie. Assia Djebar. Écrire, transgresser, résister. Paris : L’Harmattan, 1997, 173 p.] Cinémas, 10(2-3), 243-246. https://doi.org/10.7202/024826ar d'utilisation que vous pouvez consulter en ligne.

https://apropos.erudit.org/fr/usagers/politique-dutilisation/ 
CLERC, Jeanne-Marie. Assia Djebar. Écrire, transgresser, résister. Paris : L'Harmattan, 1997, 173 p.

Bien qu'Assia Djebar ait maintenant dû abandonner le cinéma pour se consacrer au roman et à l'essai, un compte rendu du livre de Jeanne-Marie Clerc sur cette auteure a cependant sa place dans Cinémas. Cette étude explore en effet une œuvre qui à ses débuts comprenait à la fois films et romans. Rares sont les travaux qui abordent la pratique de ces deux médias à propos d'un auteur ou d'une auteure en particulier. L'ouvrage de JeanneMarie Clerc est donc important, non seulement parce qu'il traite d'une figure majeure de la littérature francophone internationale, mais encore parce qu'il adopte une méthodologie pouvant servir de modèle à l'analyse d'une œuvre qui, au moyen de la caméra et de l'écriture, explore des thèmes essentiels pour notre époque.

Assia Djebar. Écrire, transgresser, résister souligne en effet la portée internationale de textes enracinés dans la diversité des cultures berbère, arabe et française. L'originalité de la cinéaste romancière, c'est aussi, à la différence d'autres auteurs maghrébins, d'avoir "ressenti le choc des cultures né des colonisations dans son déchirement mais aussi dans son enrichissement [...]" (p. 11). Par ailleurs, l'originalité de l'étude de Jeanne-Marie Clerc, c'est de suivre le parcours de cette recherche complexe d'une "identité mosaïque" à travers plusieurs thèmes qui permettent d'aborder conjointement les romans et les films tout en faisant ressortir l'apport particulier de chaque média. Les premiers romans d'Assia Djebar, La Soif (1957), Les Impatients (1958), Les Alouettes naïves (1967), qui ont été publiés avant les films, ne figurent pas dans cet ouvrage qui met au jour l'inspiration et le nouveau souffle apportés par la pratique cinématographique. 
Le premier chapitre, intitulé «Du cinéma à la littérature: naissance d'une écriture", montre que contrairement au parcours habituel, l'expérience cinématographique a servi de matrice à l'écriture romanesque grâce à la découverte d'un sujet collectif. Un film réalisé pour la télévision algérienne, La Nouba des femmes du Mont Chenoua (1978), a en effet été pour Assia Djebar l'occasion d'une triple rencontre avec les femmes de son pays, avec leur langue et avec l'Histoire, marquant ainsi un retour à l'univers maternel dont la cinéaste avait été coupée pour avoir été élevée dans la culture du Français colonisateur. Cette quête autobiographique doublée d'une réflexion sur la condition des femmes du mont Chenoua inspirera un roman paru six ans plus tard, Ombre Sultane. Un second film, La Zerda et les chants de l'oubli (1982), revisite les grandes étapes de l'histoire de la colonisation. Sa composition repose sur "l'écart entre les images exotiques des documentaires tournés à l'usage des colonstouristes et la réalité vécue par les peuples autochtones et évoquée par la bande-son» (p. 23). Assia Djebar y aurait trouvé l'idée de son roman L'Amour, la fantasia (1985). Ici, l'écriture suit une structure de montage alternant des chapitres portant sur le passé personnel de la narratrice et des chapitres relatant d'abord la conquête de 1830 , puis reprenant les entrevues du film La Nouba.

Le deuxième chapitre, "Thème et écriture de la transgression par rapport à l'interdit féminin", se réfere aux théories de Freud sur l'interdit du regard. Il s'agit tout d'abord de l'imposition du voile qui maintient même chez la femme libérée une sorte d'atavisme de victime sacrificielle. Intervient alors pour la romancière l'expérience d'une technologie tout occidentale qui, à travers l'œil de la caméra, va lui permettre de mettre en ouvre cette avidité du regard réprimée par la culture ancestrale. Le roman Vaste est la prison (1995) raconte l'expérience du tournage, début d'une transgression et d'une reconquête de l'espace interdit qui va se prolonger dans les nouvelles et les romans.

Le troisième chapitre aborde la question de la dimension autobiographique de l'œuvre d'Assia Djebar. Le parcours personnel entre deux cultures commence à s'affirmer dès le premier film. Avec La Nouba se crée l'irruption involontaire du sujet 
parlant grâce à ce nouvel outil d'écriture qu'est la caméra. Le film, une prise de recul et une prise de conscience, une quête de soi à travers la remontée dans le temps, sera suivi de quatre romans autobiographiques. La Nouba comporte deux langues: l'arabe pour le témoignage des femmes et le français pour le commentaire à la première personne. L'expérience de l'écriture cinématographique d'abord, autobiographique ensuite, permettra ainsi à la romancière de surmonter la dichotomie culturelle qui l'écartelait et à laquelle elle fait souvent allusion dans ses premiers écrits.

Le chapitre quatre aborde l'œuvre dans la perspective d'une quête historique. Les deux films recèleraient le germe d'un des thèmes récurrents des romans écrits après 1978. La caméra a donné à Assia Djebar les moyens d'élargir son expérience et de lui conférer une dimension collective par le ressourcement historique, ce réveil du passé par le présent qui est un des thèmes de La Nouba. Par ailleurs, La Zerda a correspondu à la découverte des non-dits de l'histoire officielle et de la nécessité de faire parler ces silences. C'est dans la continuité de cette découverte que se situe le livre suivant, L'Amour, la fantasia. L'Histoire des femmes va se poursuivre dans Vaste est la prison, le troisième volet romanesque de ce qu'Assia Djebar appelle son Arabian Quartet dont L'Amour, la fantasia et Ombre sultane constituaient les débuts.

Le cinquième et dernier chapitre analyse la dimension architecturale des films et des romans, qui se mêle d'ailleurs à une aspiration musicale. La Nouba, construit suivant un parallèle entre musique et discours, réussit précisément à entrelacer ces deux structures. Les rythmes des récits contés par les femmes visitées par la narratrice reprennent les divers mouvements de la musique andalouse, la nouba. Ce passage entre montage cinématographique et structure musicale se manifeste aussi dans les romans. Donc, malgré sa dimension autobiographique, on trouve dans tout l'ouvre d'Assia Djebar une "distance formelle par rapport au vécu qui puise sa source, très tôt, dans la "pudeur arabe" interdisant à la femme de parler d'elle" (p. 127).

Assia Djebar. Ecrire, transgresser, résister est donc en premier lieu une analyse poussée des romans parus entre 1980 et 1996 
suivant une approche thématique et sociocritique. Cette étude a été publiée dans la collection "Classiques pour demain " dirigée par Daniel-Henri Pageaux, qui donne la place qu'ils méritent à de grands écrivains et écrivaines contemporains de la francophonie. En second lieu, il s'agit d'un ouvrage à l'approche originale puisque Jeanne-Marie Clerc y montre, arguments convaincants à l'appui, que la pratique conjointe de deux médias peut affecter profondément le profil d'une œuvre. Il est bien connu que nombre de romanciers sont aussi scénaristes. La critique comparée s'est d'ailleurs penchée depuis quelque temps sur les interactions nées de la pratique conjointe de ces deux écritures. JeanneMarie Clerc a été parmi les premières à étudier en profondeur ce phénomène particulier au $\mathrm{XX}^{\mathrm{e}}$ siècle ${ }^{\mathrm{I}}$. Elle présente ici l'étude d'un rapport d'autant plus intéressant qu'il se situe à la croisée de deux médias. Le cinéma y apparaît comme la voie d'une révélation à la fois de contenu et de forme. Il représente d'abord l'accession à une histoire collective et à une culture effacée. En outre, sa pratique libère les ombres cachées sous les mots et dévoile les dimensions obscures enfouies dans les structures profondes du psychisme.

Parce que cette étude s'organise thématiquement plutôt que chronologiquement et qu'elle ne cesse de passer des films aux romans et vice versa, il est parfois un peu difficile pour une lectrice qui n'a pas une connaissance approfondie de l'œuvre d'Assia Djebar de s'orienter. Cependant, il faut recommander vivement cet ouvrage à ceux qui s'intéressent aux rapports intermédiatiques aussi bien qu'à celles qui aimeraient lire une analyse profonde et originale de la question du sujet identitaire et du sujet féminin.

Jacqueline Viswanathan

Simon Fraser University

\section{NOTE}

1 Voir deux ouvrages de Jeanne-Marie Clerc: Ecrivains et cinéma (Paris: Klincksieck, 1985) et Le Cinéma, témoin de l'imaginaire dans le roman français contemporain (Berne: Peter Lang, 1984). 